\title{
Protein content of minimal and ancestral ribosome
}

\author{
ARCADY MUSHEGIAN \\ Stowers Institute for Medical Research, Kansas City, Missouri 64110, USA \\ Department of Microbiology, Molecular Genetics, and Immunology, University of Kansas Medical Center, Kansas City, \\ Kansas 66160, USA
}

\begin{abstract}
Minimal genome approaches seek to define the smallest gene complement compatible with modern-type cellular life on Earth. A consensus of computational and experimental approaches indicates that a minimal genome is close to 300 protein-coding genes, if a rich medium is provided for cell growth. I relate ribosomal gene content in completely sequenced genomes to ribosomal subunit structure and approximate the protein components of the putative minimal ribosome and the ribosome of the Last Universal Common Ancestor of Life. Both sets contain between 35 and 40 proteins. There is evidence of protein-protein and protein-RNA displacement in the evolution of both ribosomal subunits.
\end{abstract}

Keywords: ribosomal proteins; comparative genomics; gene displacement

\section{INTRODUCTION}

Reconstructions of a minimal genome (Koonin 2003) suggest that it would use about half of its gene products for simplified intermediate metabolism and the other half to control genome replication, repair, and gene expression. The latter category includes ribosomal proteins. Molecular functions of most of them remain poorly understood, whereas the two essential activities of the ribosome, decoding of mRNA and synthesis of peptide bonds, appear to be largely performed by the ribosomal RNA itself (Steitz and Moore 2003).

Ribosomal proteins exist in two main flavors-Bacterial, including endosymbiont-derived proteins of mitochondrial and chloroplast ribosomes, and Archaeo/Eukaryal. More specifically, if a ribosomal protein has orthologs in all living species, the sequence-based phylogenetic tree of such orthologs tends to display the ancient bifurcation of Bacteria (B) and Archaea/Eukarya (AE), followed by a more recent split of $\mathrm{A}$ and E. If a protein is not omnipresent, it is typically found either only in B or only in AE (Anantharaman et al. 2002; Lecompte et al. 2002; see Supplementary Material, available at http://research.stowers-institute.org/bioinfo, for a description of phylogenetic and other methods used in this work, as well as for additional discussion of the Tree of Life).

Mears et al. (2002) have defined minimal ribosomal RNA as the set of rRNA regions conserved in all living forms and two types of organelles. This minimal rRNA is approxi-

Reprint requests to: Arcady Mushegian, Stowers Institute for Medical Research, 1000 E. 50th St., Kansas City, MO 64110, USA; e-mail: arm@ stowers-institute.org; fax: (816) 926-2041.

Article published online ahead of print. Article and publication date are at http://www.rnajournal.org/cgi/doi/10.1261/rna.2180205. mated by two extremely deleted rRNAs found in mitochondria of nematodes. The small-subunit (SSU) rRNA in nematode mitochondria has lost $\sim 55 \%$ of its nucleotides compared to an average bacterial homolog, the large-subunit (LSU) rRNA has lost 74\%, and 5S RNA is missing in nematode mitochondria altogether. The remaining, universally conserved rRNA domains include most of the intersubunit interface, as well as the peptidyltransferase center and the sites of interaction with tRNAs.

rRNA from any species can be partitioned into three sequence components: regions that can be aligned to nematode mito-rRNA; those that do not align to mito-rRNA, but have a structural equivalent within it, for example, a nonconserved loop joining the halves of a conserved RNA hairpin; and sequences missing from nematode mito-rRNA. The first two components together can be viewed as minimal rRNA.

The protein component of minimal ribosome has been defined as the set of all ribosomal proteins present in three phyla and two organelles (3P2O in Mears et al. 2002). Here, I refine this set and derive the protein complement of the ancestral ribosome using a comparative-genomics approach.

\section{RESULTS AND DISCUSSION}

Minimal set of ribosomal proteins Min1: Recount of shared orthologs and their interactions with minimal rRNA

A lucky DNA sample is sufficient to detect gene presence in a given species. Gene absence, however, is definitive only when the entire genome sequence is available. Therefore, 
I searched the completely sequenced genomes for sequences related to known ribosomal proteins (computational protocols are available as Supplementary Material at http:// research.stowers-institute.org/bioinfo) and recovered a larger set of ribosomal proteins than what is shown in Mears et al. (2002). Additional homologs were often already annotated as ribosomal proteins and sometimes characterized biochemically.

Presences and absences of genes in genomes, expressed as binary vectors, are called phyletic patterns (or phylogenetic profiles; Tatusov et al. 1997; Pellegrini et al. 1998; Mirkin et al. 2003). If a gene has orthologs in all genomes, its pattern consists only of ones (Table 1). In eukaryotic genomes, there may be extra copies of such genes, coding for organellular proteins (mitochondrial in fungi and metazoa, mitochondrial and chloroplast in plants), often recognizable by the prediction of targeting peptides. This is called Phyletic Pattern Level 1 (PPL1, similar to the 3P2O set in Mears et al. 2002). When a gene is found in every species, but eukaryotic orthologs are all cytoplasmic, rather than organellular, this is called PPL2. Levels 3-7 describe other types of taxonomic distribution of ribosomal proteins, all of which are of interest for the reconstruction (Table 1).

There are 32 ribosomal proteins with PPL1 (Fig. 2; see Supplementary Material, http://research.stowers-institute. org/bioinfo). To make the Min1 list, such a protein has to interact with Min rRNA. Although there is no highresolution structure of any complete ribosome, the SSU structure from the bacterium T. thermophilus and LSU structures from the bacterium Deinococcus radiodurans and the archaeon H. marismortui are known (Brodersen et al. 2002; Bashan et al. 2003; Klein et al. 2004). All told, 30 ribosomal proteins are min-rRNA interactors, and the intersection of this set with 32 PPL1 proteins gives 25 proteins, i.e., the minimal set Min1 (Figs. 1, 2). Remarkably, almost half of the SSU proteins make it to Min1, compared to only one-fifth of the proteins from the LSU. Perhaps structure-stabilizing interactions with proteins are more important for the SSU RNA, made of three relatively mobile domains, than for the LSU RNA, which seems to be more tightly packed on its own (Brodersen et al. 2002; Bashan et al. 2003).

\section{Minimal set Min2, which accounts for nonorthologous gene displacements}

Any minimal set, if it includes only shared orthologs, underestimates the number of components, because one and the same function can be performed, in two species, by nonorthologous, and sometimes even nonhomologous, proteins (Koonin 2003). This is called nonorthologous gene displacement (Koonin et al. 1996), and in the case of the enzymes of intermediate metabolism, $5 \%-10 \%$ of genes may be so displaced (Galperin and Koonin 1999). Thus far, little is known about gene displacements among ribosomal proteins. One way to account for displacements is to compare phyletic patterns, looking for pairs of proteins found to the exclusion of one another. In the case of ribosomal proteins, the candidates are obvious: Many proteins are found either only in Bacteria (PPL3-4; Table 1) or in Archaea/Eukarya (PPL5-6).

TABLE 1. Phyletic pattern levels

\begin{tabular}{|c|c|c|c|}
\hline PPL & Description & $\begin{array}{l}\text { Species } \\
\text { HMPPAMMTTSAPSSETCBBSLSSLCASBMHPVYSEEEPRXNNCMMMFDSNRRBCCTBMUMMACHj } \\
\text { bahaft jkavspycpcmashalppictmml imcptcCCasfmmglttnryopcutppbpupgajpH } \\
\text { scobuhaacooeaeouacuauaynnrueeonuheyozseoaeAleuCuansrocrnauurneeeyp }\end{array}$ & Example \\
\hline 1 and 2 & $\begin{array}{l}\text { In all species in cytoplasmic } \\
\text { ribosomes only (PPL2), or also } \\
\text { in organellular ribosomes } \\
\text { (PPL1) }\end{array}$ & 111111111111111111111111111111111111111111111111111111111111111111 & L3 \\
\hline 3 & In all bacteria but not elsewhere & 000000000000000011111111111111111111111111111111111111111111111111 & L20 \\
\hline 4 & $\begin{array}{l}\text { In all archaea/eukarya, but not } \\
\text { elsewhere }\end{array}$ & 111111111111111100000000000000000000000000000000000000000000000000 & L15E \\
\hline 5 & $\begin{array}{l}\text { Only in bacteria, but not in all } \\
\text { species }\end{array}$ & 000000000000000010110000001111111111111111111111111111111111111011 & S21 \\
\hline 6 & $\begin{array}{l}\text { Only in archaea/eukarya, but not } \\
\text { in all species }\end{array}$ & 1011110011111111000000000000000000000000000000000000000000000000000 & L30E \\
\hline 7 & $\begin{array}{l}\text { In all three domains, but not in } \\
\text { all species }\end{array}$ & 111111111111111111001111111111111111111111111111000011111100110000 & L7E \\
\hline
\end{tabular}

Species abbreviations are as in the COG database (Tatusov et al. 2003). Gray shading indicates archaea, no shading indicates bacteria. Only fungal and microsporidia genomes (yellow shading) are shown for enkaryotes. 


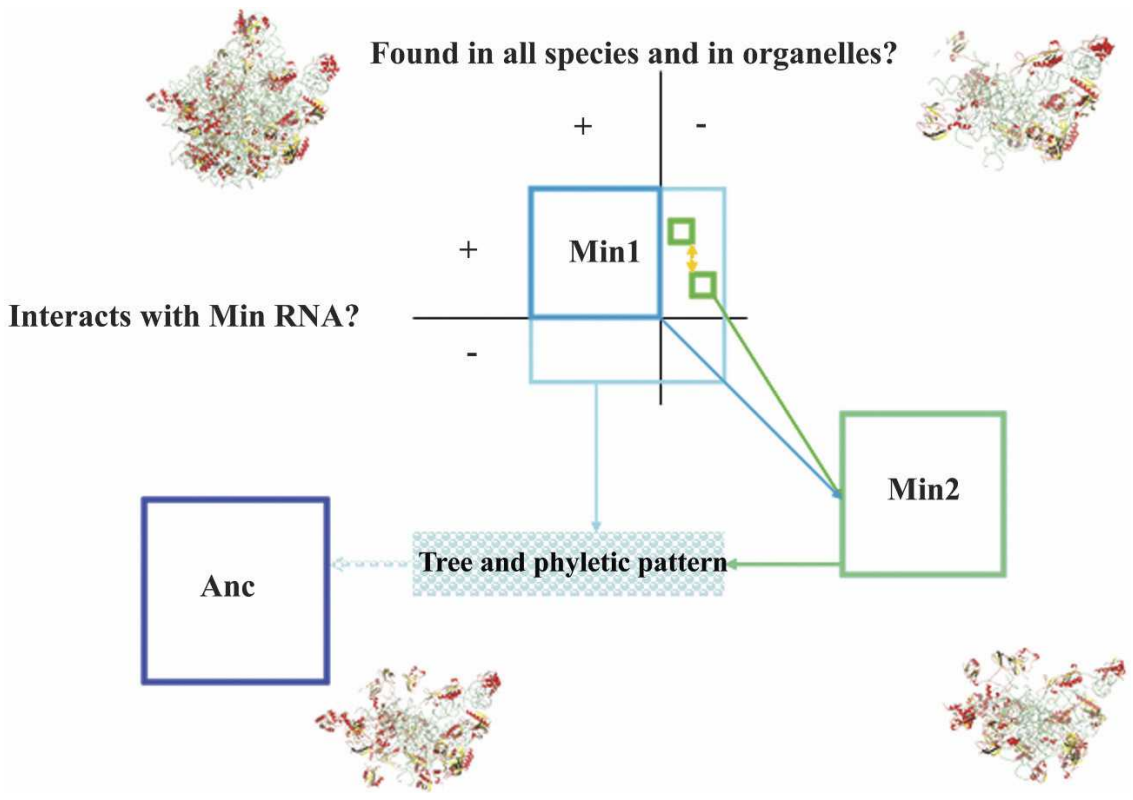

FIGURE 1. Reconstruction of Minimal and Ancestral sets of ribosomal proteins. Proteins are partitioned on the basis of their interaction with minimal RNA and presence of their orthologs in all species and organelles. Proteins that are "positive" on both counts are the Min1 set. Min2 is produced by supplementing Min1 with nonorthologous proteins found in complementary subsets of species, which interact with the homologous region of Min RNA (nonorthologous displacements). Anc is obtained by inferring the presence of ribosomal proteins in LUCA, using the phylogenetic tree and the phyletic pattern of each ribosomal protein. Cartoons of LSU at various stages of reconstruction are shown. Coordinate files for reconstructions of both subunits are available on request.

Conceivably, a protein in one such group may contain an isofunctional protein in the other.

Most ribosomal proteins have roles in properly orientating functional rRNA subdomains upon ribosome assembly and in targeting regulatory factors to specific sites on the ribosome (Klein et al. 2004). The site of specific interaction between a ribosomal protein and rRNA, therefore, can be taken as an indication of its function, and when the interaction sites of the two proteins are similar, their function may be similar too. In the case of the large subunit, one can directly identify the cases when bacterial and archaeal ribosomal proteins interact with the homologous regions on Min rRNA. Analysis of LSUs from $H$. marismortui and $D$. radiodurans identifies probable displacements at six distinct locations within the large subunit, involving nine bacterial and eight archaeal proteins.

At the exit from the peptide tunnel, archaeal protein L31E and bacterial L17 are found at the same site. This region interacts with translocon as secreted peptides are inserted into the signal recognition particle. It would be interesting to know whether the differences in this process in bacteria and archaea have to do with different L17/L31E specificities. Inside the exit tunnel, two pairs of proteins are displacing each other. Elongated L39E displaces the nonglobular tail of bacterial L23, and L37E displaces bacterial L34. In the bacterial peptidyltransferase center, L27 interacts with P-loop and
tRNA. Archaeal L21E occupies a very similar position. At the E site, bacteriaspecific L31 and L33 make contacts with helix 75 and tRNA, whereas in archaea this role is played by archaeo-eukaryal $\mathrm{L} 15 \mathrm{E}$ and L44E. At the intersubunit interface, L19 is replaced by archaeal L24E. Both proteins are thought to form bridge B6 with the SSU, where they both interact with the Min1/Min2 member S14. At the Min domain of helix 25, the joint nonglobular regions of bacterial L20 and L21 play the same role as the nonglobular part of archaeo-eukaryal L32E. These displacements are discussed in more detail in Table 2; most of them have been noticed before (Harms et al. 2001; Klein et al. 2004). After these displacement cases are added to Min1, most protein-protein interactions in the large subunit are recovered, indicating that Min2 is functionally more coherent than Min1.

\section{Anc, the ancestral set of ribosomal proteins}

There is no requirement for LUCA to possess a minimal genome. Therefore, to proceed from the Min2 to Anc set, we have to add the Min-Anc+ proteins to Min2, and to remove Min+Ancproteins. Anc ribosome is allowed to gain some rRNA in the regions that interact with $\mathrm{Min}-\mathrm{Anc}+$ proteins. One way to find the Anc+ proteins is by using phyletic patterns together with the phylogeny of the protein sequences. There are two main possibilities: Either the pattern is found in every species (PPL1/PPL2 can be combined here, because the origin of organelles clearly postdates the LUCA) or it is not (PPL3-7).

A PPL1/2 gene is scored as ancestral if there is a good agreement between the phylogenetic tree of this gene and the Tree of Life (Mirkin et al. 2003; Supplementary Material, available at http://research.stowers-institute.org/ bioinfo). The agreement of the two trees-as a first approximation, the same branching order on the protein family tree and the consensus species tree-suggests that the common ancestor of a given gene was present in LUCA, and the gene must have been acquired by the observed species mostly by vertical inheritance. If, however, there is significant difference between the topologies of the species' tree and the gene tree, or if gene is missing in too many species, the ancestral state of the affairs is obscured. To reconcile the trees and to infer the status of such a gene in the common ancestor, one has to account for lineagespecific gene gains and losses and horizontal transfers (Arvestad et al. 2003; Mirkin et al. 2003). I tested the 


\begin{tabular}{|c|c|c|c|c|c|c|c|c|c|c|}
\hline & $\begin{array}{l}\text { PDB } \\
\text { chain }\end{array}$ & $\begin{array}{l}\text { Protein } \\
\text { complex }\end{array}$ & PPL & $3 \mathrm{P}$ & $3 \mathrm{P} 2 \mathrm{O}$ & \begin{tabular}{|l|} 
Min rRNA \\
interactions
\end{tabular} & \begin{tabular}{l|} 
Min1 \\
\end{tabular} & Min2 & $\begin{array}{l}\text { Anc } / \\
\text { LUCA }\end{array}$ & $\begin{array}{l}\text { NCBI } \\
\text { COG }\end{array}$ \\
\hline S2 & $\mathrm{b}$ & bdehq & 1 & & & & & & & \\
\hline S3 & $\mathrm{c}$ & cijmns & 1 & & & & & & & 0092 \\
\hline S4 & $\mathrm{d}$ & bdehq & 1 & & & & & & & 0522 \\
\hline S5 & e & bdehq & 1 & & & & & & & 0098 \\
\hline S6 & $f$ & fgkr & 3 & & & & & $?$ & $?$ & 0360 \\
\hline S7 & g & fgkr & 1 & & & & & & & 0049 \\
\hline s8 & $\mathrm{h}$ & bdehq & 1 & & & & & & & 0096 \\
\hline S9 & $i$ & cijmns & 1 & & & & & & & 0103 \\
\hline s10 & j & cijmns & 1 & & & & & & & 0051 \\
\hline S11 & $\mathrm{k}$ & fgkr & 1 & & & & & & & 0100 \\
\hline S12 & 1 & & 1 & & & & & & & 0048 \\
\hline S13 & $\mathrm{m}$ & cijmns & 1 & & & & & & & 0099 \\
\hline S14 & $\mathbf{n}$ & cijmns & 2 & & & & & & & 0199 \\
\hline S15 & $\circ$ & & 2 & & & & & & & 0184 \\
\hline S16 & $p$ & & 3 & & & & & $?$ & $?$ & 0228 \\
\hline $\mathbf{S 1 7}$ & $q$ & bdehq & 1 & & & & & & & 0186 \\
\hline S18 & $\frac{1}{r}$ & fgkr & 3 & & & & & $?$ & ? & 0238 \\
\hline S19 & s & cijmns & 1 & & & & & & & 0185 \\
\hline L1 & & & 1 & & & & & & & 0081 \\
\hline $\mathrm{L} 2 / \mathrm{L} 8$ & $a$ & $\mathrm{a}(\mathbf{z})$ & 1 & & & & & & & 0090 \\
\hline $\mathrm{L} 3$ & $\mathrm{~b}$ & bejk(u) & 2 & & & & & & & 0087 \\
\hline L4 & $\mathrm{c}$ & $c z$ & 2 & & & & & & & 0088 \\
\hline L6 & e & bejk(u) & 2 & & & & & & & 0097 \\
\hline L7E & $f$ & $\mathrm{fm} 3$ & 7 & & & & & & & 1841 \\
\hline L10 & g & & 2 & & & & & & & 0244 \\
\hline L10E/L16 & $\mathrm{h}$ & & 1 & & & & & & & 0197 \\
\hline L11 & $i$ & & 1 & & & & & & & 0080 \\
\hline L13 & $j$ & bejk(u) & 2 & & & & & & & 0102 \\
\hline L14 & $\mathrm{k}$ & bejk(u) & 2 & & & & & & & 0093 \\
\hline L15 & 1 & & 2 & & & & & & & 0200 \\
\hline L15E & $\mathrm{m}$ & $f m 3$ & 5 & & & & & L31/L33 & $?$ & 1632 \\
\hline L21E & q & (dn)q & 5 & & & & & L27 & $?$ & 2139 \\
\hline L22 & $r$ & & 1 & & & & & & & 0091 \\
\hline L23 & $\mathrm{s}$ & & 1 & & & & & & & 0089 \\
\hline L24E & $\mathrm{u}$ & & 5 & & & & & L19 & $?$ & 2075 \\
\hline L24P & $t$ & & 1 & & & & & & & 0198 \\
\hline L31E & $\mathrm{x}$ & & 5 & & & & & L17 & $?$ & 2097 \\
\hline L32E & $\mathrm{y}$ & & 5 & & & & & L20/L21 & $?$ & 1717 \\
\hline L37E & $z$ & cz & 5 & & & & & $\mathrm{~L} 23 / \mathrm{L} 34$ & $?$ & 2126 \\
\hline L39E & 1 & & 5 & & & & & $\mathrm{~L} 23 / \mathrm{L} 34$ & $?$ & 2167 \\
\hline L44E & 3 & $\mathrm{fm} 3$ & 5 & & & & & L31/L33 & $?$ & 1631 \\
\hline
\end{tabular}

FIGURE 2. Protein content of Min1, Min2, and Anc. The chain identifiers for each molecule in the PDB file (1FJG for Thermus small ribosomal subunit and 1S72 for Haloarcula large subunit) are shown in the second column. Groups of proteins linked by proteinprotein interactions are shown in the third column. Gray shading indicates that a protein belongs to the set shown at the top of the column, and a blank cell indicates that this protein is not a member of this set. Red cells indicate possible gene displacements, marked by question marks in the case of a small subunit and annotated in the case of a large subunit (cf. Table 2). The blue cell is a special case of S8 (see text). Yellow cells are proteins that join the Anc set because they have PPL1 and a compatible phylogenetic tree, and the green cell is L7E (PPL7), added to the Anc set by maximum-likelihood analysis of its phyletic pattern. The question marks in the Anc/LUCA column indicate that it is not known which version of this component (Bacterial, Archaeo/Eukaryal, or maybe RNA) was present in the LUCA.

ancestral hypothesis for all proteins with PPL1-2, and three of them, all in the LSU, showed the same topology as the consensus species' tree. These three proteins, L1, L23, and L24P, join the Anc set.

Given an explicit model of gene gains and losses, the compatibility of any "patchy" phyletic pattern and gene presence in LUCA can be quantitatively assessed (Mirkin et al. 2003; Supplementary Material, available at http://research. stowers-institute.org/bioinfo). I examined the phyletic patterns PPL3-7, and for one PPL7 protein, L07E, the hypothesis of its presence in LUCA was better supported than the alternative.
Several PPL1 proteins have unusual phylogenies: S14 in bacteria has undergone horizontal transfers and takeovers of gene function by a phylogenetically distant ortholog (Brochier et al. 2000), and two proteins, S15 and L01, branch unexpectedly deeply in Treponema and Chlamydia, respectively. All this overprinting, however, appears to have occurred within Bacteria, i.e., post-LUCA, and these proteins remain in the Anc set.

Direct analysis of gene displacements cannot be done for SSU because the structure is available only for a bacterial representative. However, three bacteria-specific proteins with PPL3, namely, S6, S16, and S18, contact Min-rRNA and may be displaced in archaea. In particular, S6 and S18 are part of the T4 RNP complex, which also includes Min and Anc protein S15 and helices 20 and 23 from Min-rRNA (Agalarov et al. 2000). S16, thought to play an auxiliary role in the assembly of that complex, interacts with the conserved end of helix 15. In archaeal SSU, there are seven AE/ PPL5 proteins, not mapped to specific locations in a ribosome yet. Further studies of these proteins will test the prediction that some of them are displacing bacterial S6, S16, and S18 in archaeo/eukaryotic ribosome. I tentatively add S6, S16, and S18 to Min2 and Anc.

In Thermus SSU, a tiny, poorly structured THX protein interacts with several conserved regions of rRNA Domain III. A database search using the PSI-BLAST program (Altschul et al. 1997) suggests that THX is orthologous to ribosomal protein S31, known from chloroplasts and two plant-associated bacteria, Xylella and Xanthomonas (A. Mushegian, unpubl. observations). It is possible that counterparts of THX are found outside of this handful of genomes, but have not been recognized because of their small size or low sequence identity. Alternatively, they may be displaced by other proteins.

A more radical proposition is that some nonorthologous displacements may involve a protein and an RNA, i.e., the function of a deleted rRNA element is taken over by an extra protein or an insertion of additional nucleotides in rRNA obviates a need for a ribosomal protein. The most relevant observation here concerns the interactions between proteins and a nonminimal region of the LSU RNA. In the alignment of Haloarcula and Deinococcus RNA, there is a single long (50 bases) insert, which forms an extra length in RNA helix 25 in Haloarcula. This region of rRNA interacts with the globular domain of archaeal L32E protein. In bacteria, L32E is displaced by L20 and L21 (Klein et al. 2004; Table 2), but the RNA site that interacts with the L32E globular domain in archaea is not found in bacteria. Interestingly, however, bacterial L20 makes extensive contacts with the globular portion of L21, which, in turn, contacts L15 (PDB entry 1NKW). Thus, the archaea-specific extension of RNA helix 25 and the globular domain of bacteria-specific L21 may be isofunctional, yet they are obviously nonorthologous.

Another suggestion of an RNA-protein displacement comes from the unique case of protein S8. It interacts with SSU RNA 
TABLE 2. Nonorthologous displacements of ribosomal proteins

\begin{tabular}{|c|c|c|c|c|c|}
\hline $\begin{array}{l}\text { Ribosome } \\
\text { functional site }\end{array}$ & $\begin{array}{l}\text { Bacterial protein } \\
\text { (PDB ID 1NKW) }\end{array}$ & $\begin{array}{l}\text { Fold } \\
\text { class }^{\mathrm{a}}\end{array}$ & $\begin{array}{c}\text { Archaeo/Eukaryal } \\
\text { protein (PDB ID 1S72) }\end{array}$ & $\begin{array}{l}\text { Fold } \\
\text { class }^{\mathrm{a}}\end{array}$ & Comments \\
\hline Exit tunnel opening & L17 (L) & 4 & L31E (W) & 4 & $\begin{array}{l}\text { These proteins are from the different } \\
\text { superfamilies of the broad } \alpha+\beta \text { fold } \\
\text { class, and have no sequence similarity. }\end{array}$ \\
\hline \multirow[t]{2}{*}{ Exit tunnel interior } & L23 (R) & $3-4$ & L39E (1) & 1 & \multirow[t]{2}{*}{ See main text. } \\
\hline & L34 (2) & 1 & L37E (Z) & 2 & \\
\hline \multirow[t]{2}{*}{ Helix 25 (common part) } & L20 (O) & 1 & L32E (X) & 3 & \multirow[b]{2}{*}{$\begin{array}{l}\text { A } 45 \text {-amino-acid loop in the middle of } \\
\text { L32E protein penetrates the ribosome } \\
\text { body, interacts with the min-rRNA } \\
\text { region of helix } 25 \text {, and makes some of } \\
\text { the same RNA contacts as the extended } \\
\text { regions of two proteins, L20 and L21, in } \\
\text { bacteria. Typical of ribosomal proteins, } \\
\text { L32E and L21 have many positively } \\
\text { charged residues in these regions, but } \\
\text { there is no clear indication of an } \\
\text { evolutionary relationship. }\end{array}$} \\
\hline & L21 (P) & 2 & & 3 & \\
\hline P-loop, P-tRNA & L27 (U) & 2 & L21E (P) & 2 & $\begin{array}{l}\text { The same fold class, and some shared } \\
\text { features, such as the strongly twisted } \\
\beta \text {-sheet, but no specific sequence } \\
\text { similarity between L27 and L21E. }\end{array}$ \\
\hline \multirow[t]{2}{*}{ Helix 75, E-tRNA } & L31 (Y) & 3 & L15E (L) & 4 & \multirow[b]{2}{*}{$\begin{array}{l}\text { The } \alpha-\beta \text { region of } L 15 E \text { interacts only with } \\
\text { non-Min rRNA and is not considered } \\
\text { further. Elongated regions of L15E and } \\
\text { L44E contact each other, helix } 75 \text {, and } \\
\text { E-tRNA. This composite protein } \\
\text { structure is replaced by a single protein, } \\
\text { L31, in bacteria. The globular part of } \\
\text { L44E also interacts with E-tRNA, and is } \\
\text { replaced by a globular protein L33 in } \\
\text { bacteria. The folds of L33 and L44E are } \\
\text { similar, and there is significant } \\
\text { sequence similarity between L33 and } \\
\text { L44E, covering most of the length of the } \\
\text { shorter L33. The order of related } \\
\text { sequence segments, however, is } \\
\text { swapped. Thus, L33 and the globular } \\
\text { part of } L 44 \mathrm{E} \text { may be orthologs in } \\
\text { disguise (Klein et al. 2004), properly } \\
\text { belonging in Min } 1 / \text { Min2. }\end{array}$} \\
\hline & L33 (1) & 2 & L44E (2) & 2 & \\
\hline Intersubunit bridge B6 & L19 (N) & 2 & L24E (T) & 2 or 5 & $\begin{array}{l}\text { L19 and L24E are dissimilar at the } \\
\text { sequence level. Both L19 and L24E, } \\
\text { however, donate two } \beta \text {-strands in a } \\
\text { similar way, to form an interprotein } \\
\beta \text {-sheet with S14. }\end{array}$ \\
\hline
\end{tabular}

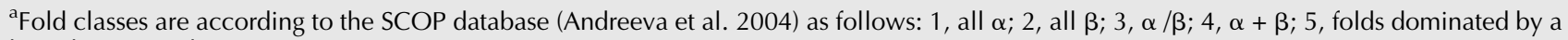
ligand or a metal ion.

mostly via helices 21, 22, and 25 (numbering as in Agalarov et al. 2000), which do not belong to Min rRNA. I included S8 in Min1/Min2 because it has PPL1 and bridges, via multiple protein-protein interactions, the Min1 members S2 and S17 (Fig. 3). Interestingly, a bacterial-like S8 homolog is encoded by the nuclear genome of Caenorhabditis elegans (F53A3.3; gi 2429452). It most likely operates in mitochondria, but nematode mitochondrial RNA appears to lack the targets of S8 interaction. Perhaps missing RNA segments are functionally replaced by extra proteins in nematode mitochondrial ribosome. Several hundred poorly characterized proteins in $C$. elegans are predicted to encode mitochondrial targeting peptides, and some of these proteins contain putative nucleic-acidbinding domains with S4, KH, or Ob folds (A. Mushegian, unpubl. observations). It would be interesting to know whether any of them are found within nematode mitochondrial ribosomes. 


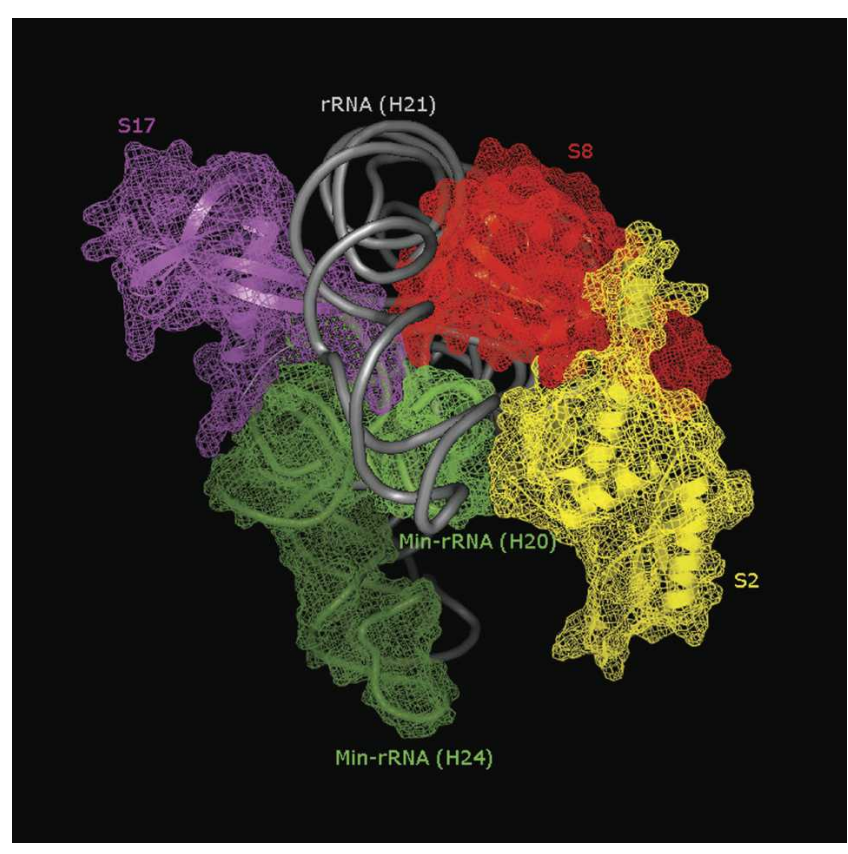

FIGURE 3. Interactions of bacterial SSU protein S8 with rRNA and Min1 proteins. The coordinates of Thermus SSU components are from PDB entry 1FJG. Helices $(\mathrm{H})$ are numbered according to Agalarov et al. (2000) and Mears et al. (2002). For details, see text.

I reconstructed the protein complement of minimal and ancestral ribosomes by comparative analysis of sequences, structures, and phyletic patterns of ribosomal components. In all divisions of Life combined, there are at least 60 nonorthologous ribosomal proteins. One result of this work is that both Min and Anc sets contain a large fraction of those proteins-at least 35 in Min2 and $\sim 40$ in Anc. Some of the Anc components are shared by all present divisions of Life, while others are arranged in pairs, in which a bacterial/organellular form and an archaeal/eukaryotic form displace each other. It is not clear which of these alternative forms, or maybe their RNA counterpart, was present in LUCA. Almost all of these displacements were noticed by Harms et al. (2001) or by Klein et al. (2004). Harms et al. did not consider evolutionary implications, and Klein et al. interpreted gene displacements between ribosomal proteins as the direct evidence that in LUCA the role of each such protein had been played by rRNA. In contrast, I suggest that both RNA-protein and proteinprotein displacements have been possible in the evolution of ribosome. It would be interesting to try engineering some of them using the present-day ribosomes.

Full activity of a ribosome requires several types of covalent modifications of rRNA and proteins. Although these factors were not analyzed in detail here, it is notable that most reconstructions of minimal and ancestral gene sets include at least one pseudouridylate synthase, several RNA methyltransferases, and chaperones that mediate ribosome maturation (Anantharaman et al. 2002; Koonin 2003; Mushegian 2004).

Among the ancestral ribosomal proteins, there are representatives of all currently recognized classes of protein structures (Andreeva et al. 2004). Notably, however, in both Min2 and Anc sets, the all- $\alpha$ proteins and small ligand-dominated proteins are underrepresented, and proteins enriched in $\beta$ sheets are overrepresented, compared to ribosomal proteins as a whole (see Supplementary Material, at http://research. stowers-institute.org/bioinfo). This may have interesting implications for the origin and evolution of pre-LUCA ribosomes and proteins in general. As a more practical matter, the Min and Anc sets outlined here provide a blueprint to begin engineering a minimal ribosome in earnest.

\section{MATERIALS AND METHODS}

The outline of the approach is as follows. A trait (e.g., gene) is "minimal" (Min) if an organism needs this gene for survival. A gene in a present-day species is "ancestral" (Anc) if a particular ancestor of the species had an ortholog of this gene.

This work relies on the Min-rRNA model. I use Min-rRNA as it has been defined by Mears et al. (2002). Sequences of rRNAs with known three-dimensional structure were aligned to the nematode mitochondrial rRNA using the utilities at the CRW resource (Cannone et al. 2002) and manually edited to reflect the model, as depicted in Figure 3 of Mears et al. (2002). To define RNAprotein interactions, I used PDB entries 1FJG (Thermus thermophilus small ribosomal subunit) and 1 S72 (Haloarcula marismortui large subunit) and computed all cases when at least one atom in a polypeptide chain was within $3.5 \AA$ from any atom of rRNA. Though only one such pair of atoms was required for registering a protein-RNA interaction, in fact all interactions detected in that way involved multiple amino acids in one protein and, for each interacting protein, multiple bases in rRNA. Bridging by water or inorganic ions was not considered. Methods of sequence and structure comparison and phylogenetic inference are discussed in more detail in the Supplementary Material (http://research. stowers-institute.org/bioinfo).

The first goal of this work is to reconstruct the Min set of ribosomal proteins. Mears et al. (2002) listed 22 proteins that have orthologs in 3P2O-13 in SSU and 9 in LSU. A recount indicates that the list of ribosomal proteins found in $3 \mathrm{P} 2 \mathrm{O}$ is longer, and yet, I propose that only some of these proteins are truly Min, namely, those that have cognate interaction sites in Min rRNA. The intersection of omnipresent proteins and proteins that bind Min rRNA gives the Min 1 set of ribosomal proteins. Next, this set is supplemented with isofunctional proteins, i.e., nonorthologous counterparts in Bacteria and Archaea that interact with orthologous regions of rRNA in a similar way. Addition of these proteins produces Min2, the current estimate of the protein complement of minimal ribosome.

To reconstruct the Anc set, a specific ancestor has to be fixed. I focus on the common ancestor of the $\mathrm{B}$ and $\mathrm{AE}$ branches, called LUCA, the Last Universal Common Ancestor (Forterre and Philippe 1999; Mirkin et al. 2003). Because any protein belongs to one of four categories-Min+Anc+, Min-Anc-, Min+Anc-, Min-Anc+- one can proceed from Min2 to LUCA ribosome by finding Min+Anc- proteins and removing them from Min2, and 
then finding Min-Anc+ proteins in the databases and adding them to the final list (Figure 1). Both steps rely on examination of the phylogenetic trees and phyletic patterns of all ribosomal proteins.

\section{ACKNOWLEDGMENTS}

I thank Galina Glazko for assistance with phyletic pattern analysis, Michael Coleman for assistance with programming, Shura Mankin for critically reading the manuscript, and an anonymous reviewer for helpful comments and for prompting a crucial correction regarding the case of S8 protein. This work is supported by Stowers Institute for Medical Research. The author declares that he has no competing financial interests.

Received January 27, 2005; accepted June 6, 2005.

\section{REFERENCES}

Agalarov, S.C., Sridhar Prasad, G., Funke, P.M., Stout, C.D., and Williamson, J.R. 2000. Structure of the S15, S6, S18 complex: Assembly of the 30S ribosome central domain. Science 288: 107-113.

Altschul, S.F., Madden, T.L., Schaffer, A.A., Zhang, J., Zhang, Z., Miller, W., and Lipman, D.J. 1997. Gapped BLAST and PSIBLAST: A new generation of protein database search programs. Nucleic Acids Res. 25: 3389-3402.

Anantharaman, V., Koonin, E.V., and Aravind L. 2002. Comparative genomics and evolution of proteins involved in RNA metabolism. Nucleic Acids Res. 30: 1427-1464.

Andreeva, A., Howorth, D., Brenner, S.E., Hubbard, T.J., Chothia, C., and Murzin, A.G. 2004. SCOP database in 2004: Refinements integrate structure and sequence family data. Nucleic Acids Res. 32: D226-D229.

Arvestad, L., Berglund, A.C., Lagergren, J., and Sennblad, B. 2003. Bayesian gene/species tree reconciliation and orthology analysis using MCMC. Bioinformatics 19: Suppl 1:i7-15.

Bashan, A., Agmon, I., Zarivach, R., Schluenzen, F., Harms, J., Berisio, R., Bartels, H., Franceschi, F., Auerbach, T., Hansen, H.A., et al. 2003. Structural basis of the ribosomal machinery for peptide bond formation, translocation, and nascent chain progression. Mol. Cell 11: 91-102.

Brochier, C., Philippe, H., and Moreira, D. 2000. The evolutionary history of ribosomal protein RpS14: Horizontal gene transfer at the heart of the ribosome. Trends Genet. 16: 529-533.

Brodersen, D.E., Clemons Jr., W.M., Carter, A.P., Wimberly, B.T., and Ramakrishnan, V. 2002. Crystal structure of the 30 S ribosomal subunit from Thermus thermophilus: Structure of the proteins and their interactions with 16 S RNA. J. Mol. Biol. 316: 725-768.
Cannone, J.J., Subramanian, S., Schnare, M.N., Collett, J.R., D’Souza, L.M., Du, Y., Feng, B., Lin, N., Madabusi, L.V., Muller, K.M., et al. 2002. The Comparative RNA Web (CRW) Site: An online database of comparative sequence and structure information for ribosomal, intron, and other RNAs. BMC Bioinformatics 3: 2.

Forterre, P. and Philippe, H. 1999. The last universal common ancestor (LUCA), simple or complex? Biol. Bull. 196: 373-375.

Galperin, M.Y. and Koonin, E.V. 1999. Functional genomics and enzyme evolution. Homologous and analogous enzymes encoded in microbial genomes. Genetica 106: 159-170.

Harms, J., Schluenzen, F., Zarivach, R., Bashan, A., Gat, S., Agmon, I., Bartels, H., Franceschi, F., and Yonath, A. 2001. High resolution structure of the large ribosomal subunit from a mesophilic eubacterium. Cell 107: 679-688.

Klein, D.J., Moore, P.B., and Steitz, T.A. 2004. The roles of ribosomal proteins in the structure assembly, and evolution of the large ribosomal subunit. J. Mol. Biol. 340: 141-177.

Koonin, E.V. 2003. Comparative genomics, minimal gene-sets and the last universal common ancestor. Nat. Rev. Microbiol. 1: 127-136.

Koonin, E.V., Mushegian, A.R., and Bork, P. 1996. Non-orthologous gene displacement. Trends Genet. 12: 334-336.

Lecompte, O., Ripp, R., Thierry, J.C., Moras, D., and Poch, O. 2002. Comparative analysis of ribosomal proteins in complete genomes: An example of reductive evolution at the domain scale. Nucleic Acids Res. 30: 5382-5390.

Mears, J.A, Cannone, J.J, Stagg, S.M, Gutell, R.R., Agrawal, R.K., and Harvey, S.C. 2002. Modeling a minimal ribosome based on comparative sequence analysis. J. Mol. Biol. 321: 215-234.

Mirkin, B.G., Fenner, T.I., Galperin, M.Y., and Koonin, E.V. 2003. Algorithms for computing parsimonious evolutionary scenarios for genome evolution, the last universal common ancestor and dominance of horizontal gene transfer in the evolution of prokaryotes. BMC Evol. Biol. 3: 2.

Mushegian, A. 2004. Evolution and function of processosome, the complex that assembles ribosomes in eukaryotes: Clues from comparative sequence analysis. In Practical bioinformatics. Nucleic acids and molecular biology (ed. J. Bujnicki), pp. 191-219. SpringerVerlag, Berlin.

Pellegrini, M., Marcotte, E.M., Thompson, M.J., Eisenberg, D., and Yeates, T.O. 1998. Assigning protein functions by comparative genome analysis: Protein phylogenetic profiles. Proc. Natl. Acad. Sci. 96: 4285-4288.

Steitz, T.A. and Moore, P.B. 2003. RNA, the first macromolecular catalyst: The ribosome is a ribozyme. Trends Biochem. Sci. 28: 411-418.

Tatusov, R.L., Koonin, E.V., and Lipman, D.J. 1997. A genomic perspective on protein families. Science 278: 631-637.

Tatusov, R.L., Fedorova, N.D., Jackson, J.D., Jacobs, A.R., Kiryutin, B., Koonin, E.V., Krylov, D.M., Mazumder, R., Mekhedov, S.L., Nikolskaya, A.N., et al. 2003. The COG database: An updated version includes eukaryotes. BMC Bioinformatics 4: 41 . 

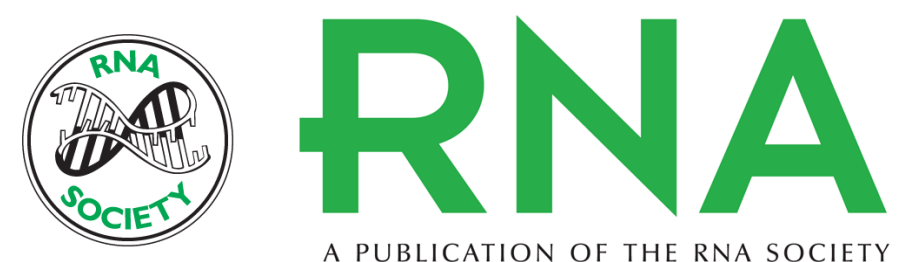

A PUBLICATION OF THE RNA SOCIETY

\section{Protein content of minimal and ancestral ribosome}

\section{ARCADY MUSHEGIAN}

RNA 2005 11: 1400-1406

References This article cites 21 articles, 2 of which can be accessed free at:

http://rnajournal.cshlp.org/content/11/9/1400.full.html\#ref-list-1

License

Email Alerting Receive free email alerts when new articles cite this article - sign up in the box at the Service top right corner of the article or click here. 